\title{
Mobile Apps as a Tool to Provide Humanized Home Care
}

\author{
Anelvira de Oliveira Florentino ${ }^{1}$, Alessandro Lia Mondelli ${ }^{1}$, Guilherme Correa Barbosa ${ }^{1}$, Ana Silvia Sartori \\ Barravieira Seabra Ferreira ${ }^{1}$, Silvia Cristina Mangini Bocchi ${ }^{1} \&$ Cassia Holtz ${ }^{1}$ \\ ${ }^{1}$ Postgraduate Program in Professional Nursing, Paulista State University, Botucatu, Brazil \\ Correspondence: Anelvira Florentino, Postgraduate Program in Professional Nursing, Paulista State University, \\ Botucatu, Brazil.
}

Received: February 19, 2021

Accepted: July 15, 2021

Online Published: July 30, 2021

doi:10.20849/ijsn.v6i3.915

URL: https://doi.org/10.20849/ijsn.v6i3.915

\begin{abstract}
Background: The present study emphasizes effective, quality, individualized and humanized care, in addition to reducing the wait for care in emergency rooms and reducing the costs of institutions providing health services. Objective: Identify how mobile applications can enable the provision of quality, fast and humanized nursing home care to the patient. Method: It is an integrative literature review, in which the Health Sciences Descriptors "biomedical technology", "home care", "nursing care" and "smartphone" were used, in the time frame between 2017 and 2020 in the databases PubMed Central data, Database in Nursing and Latin American and Caribbean Literature in Health Sciences. For the analysis, the Content Thematic was established. Results: Eleven studies were selected that met the eligibility criteria, resulting in the thematic categorization divided into: Development of applications for health care, assessment and education and Use of applications for health care. Conclusion: Assistance applications have their validity and importance, such as monitoring and welcoming the patient, as well as recording the patient's history in each application, however, assistance at home prevents the patient's displacement, waits in service queues, in addition to consist of individualized and humanized care, as valued by the holistic view that nursing and health professionals in general must have to provide healthcare.
\end{abstract}

Keywords: technology assessment, biomedical, home nursing, nursing care, nursing, access to essential medicines and health technologies

\section{Introduction}

Nowadays, it is observed that the use of computing and mobile communications technologies, such as more versatile cell phones, with data processing functions (smartphones) and portable devices (tablets) with high-speed Internet access, is constantly evolving, promoting many transformations for society.

The insertion of this technology has been progressively offering applications (small programs or software installable on mobile platforms), which provide several benefits and agility, among them in the health area, both in research and in assistance and in the management of care.

In response to this reality, there is a growing need in all areas, including health care, for the implementation of technological resources in the performance of nursing through applications in home patient care.

\section{Background}

Home Care (HC) is a health intervention strategy that requires qualified professional attention, as it is recognized that this type of care requires mobilization of specific skills, mainly linked to interpersonal relationships to work with users, family members and in a multidisciplinary team, as well as autonomy, responsibility, and technical-scientific knowledge specific to the field.

However, it is understood that care in $\mathrm{HC}$ is innovative and peculiar in health, with the potential to provide care centered on the demands and needs of the user, and it is essential that nurses have technical-scientific knowledge, as well as sociocultural, ethical, aesthetic, and intuitive, relating theory and practice, in a continuous search for updating.

The work of nurses in HC therefore involves complexity and requires flexibility, creativity and adaptation to the reality conferred by environmental, cultural, and social differences. The nurse is one of the most active and closest professionals to the nursing team, enabling the support and coordination of activities and planning, 
together with the team, the necessary interventions for the user's health, which makes their work recognized and valued.

The home care modality aims to provide assistance for shorter periods, commonly in acute cases for the completion of treatment and / or adaptation of the user and family to new care situations. This form of care contributes to cost reduction, since it provides a reduction in the time and number of hospitalizations and minimizes the demand for emergency care services. Thus, it provides "more qualified care for users with functional dependence, such as those with chronic conditions, [...] which justifies the large-scale investment in this type of care".

The possibility of $\mathrm{HC}$ providing a resolutive and effective care, enabling the construction of a therapeutic project consistent with the real possibilities and demands of the user.

\subsection{Problem Statement}

Given the above, the present study is justified by the relevance that the use of technologies (applications) has for the current scenario, which emphasizes effective, quality, individualized and humanized care, in addition to reducing the wait for care in the emergency room. and reducing the costs of institutions providing health services.

\subsection{Purpose Statement}

The purpose of this study was to identify how mobile apps can enable the delivery of quality, fast and humanized nursing home care to the patient.

\subsection{Research Question}

How mobile apps can enable the provision of quality, fast and humanized nursing home care to the patient?

\section{Method}

\subsection{Study Type}

This is an integrative literature review, with a descriptive character and a qualitative approach. This research is part of the Project entitled "Use of an application to carry out the nursing process in home care" of the Postgraduate Program in Professional Nursing, in the form of a Doctorate, from the São Paulo State University "Júlio de Mesquita Filho" / Faculty of Medicine of Botucatu (FMB), São Paulo, Brazil.

\subsection{Methodological Procedures}

A given on-screen review was guided by six stages of elaboration: definition of the guiding question, establishment of the databases and effective search in the literature, data collection from the selection of studies, critical analysis of the selected studies, discussion of the results and synthesis a from the writing of the study.

In view of the above, the following guiding question was elaborated: "How can mobile applications enable the provision of quality, fast and humanized nursing home care to the patient?"

\subsection{Data Collection and Organization}

In order to respond to the proposal, the Medical Subject Headings (MeSH), available at https://decs.org.br, were selected: "Home Assistance", "Culturally Appropriate Technology", "Biomedical Technology" and "Care of nursing". Although the descriptor "Culturally Appropriate Technology" was not widely used, we sought to perform the search in the correct way, according to the guidelines of the Virtual Health Library (VHL)/BIREME.

For the search, carried out in May 2020, the electronic databases were selected: PubMed Central (PMC), Nursing Database (BDENF) and Latin American and Caribbean Literature in Health Sciences (LILACS). As a search strategy, the Boolean operator "AND" was used".

Regarding the eligibility criteria, the following inclusion criteria were established: studies in article format; published in the time frame between 2017 and 2020, in view of the new requirements and changes in the scope of scientific publishing in nursing with the lag of the studies after 2 years of publication, with direct influence of the evaluation / classification of the Impact Factor that is carried out at every 2 years; in Portuguese and English; and studies that addressed the issue proposed here. Exclusion criteria: articles in duplicate in the chosen databases and that were not available in full text.

When searching for "Home Care AND Culturally Appropriate Technology AND Biomedical Technology AND Nursing Care" and "Home Care AND Culturally Appropriate Technology AND Biomedical Technology", no studies were found in the three bases. Thus, when using: "Biomedical technology AND home care AND nursing care", 18 studies were found, of which 01 was not in full text, 01 in Spanish, 01 in French and 01 in duplicate 
were excluded by the established criteria. For reading, 10 published in PMC, 05 in LILACS and 01 in BDENF were selected. In view of the research question, 06 studies by PMC and 01 that appeared in BDENF. In the second survey, the search strategy "Smartphone AND Home Care AND Nursing Care" was used. In this combination, 12 studies were found, 11 in PMC and 01 in LILACS, which were selected for the present review, except for one study from PMC for not presenting the theme in focus. The complete search is presented according to the guidelines of the Main Items for Reporting Systematic Reviews and Meta-analyzes - PRISMA (MOHER et al, 2015), as shown in Figure 1.

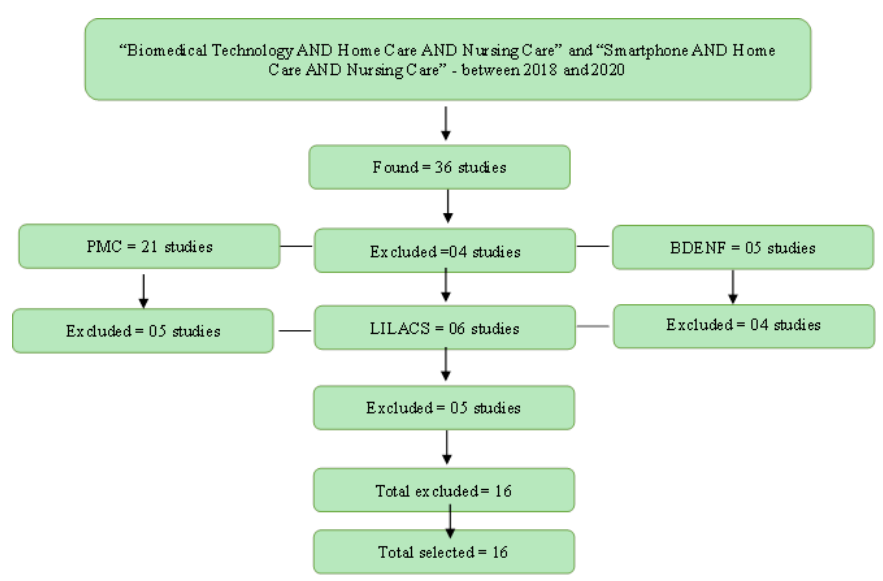

Figure 1. Flowchart of search and selection of studies

Botucatu, SP, Brazil, 2020.

\subsection{Data Analysis}

The analysis was done in a thematic way in relation to the content, methodology proposed by Bardin and resulting in thematic categorization divided into: Development of health care applications, assessment and education and Use of health care applications.

\section{Results}

At the end of the process, 16 studies published between 2018 and 2020 in the PMC, LILACS and BDENF databases were selected, which are summarized in the synoptic table referred to in Table 1.

Table 1. Synoptic table of the selected studies (Botucatu, SP, Brazil, 2020)

\begin{tabular}{|c|c|c|c|c|}
\hline Title & Year & $\begin{array}{l}\text { Study } \\
\text { Type }\end{array}$ & Objective & Conclusion \\
\hline $\begin{array}{l}\text { Improving the quality of } \\
\text { pressure } \\
\text { management in a skilled } \\
\text { nursing facility }\end{array}$ & 2019 & $\begin{array}{l}\text { Original } \\
\text { Article }\end{array}$ & $\begin{array}{l}\text { Elaborate digital wound } \\
\text { management solution was } \\
\text { adopted to track wound } \\
\text { management. }\end{array}$ & $\begin{array}{l}\text { Emphasizing the power of } \\
\text { effective management combined } \\
\text { with real-time data analysis, as } \\
\text { enabled by digital wound } \\
\text { management, to make significant } \\
\text { improvements in healthcare } \\
\text { delivery. }\end{array}$ \\
\hline $\begin{array}{l}\text { mHealth applications as } \\
\text { an educational and } \\
\text { supportive resource for } \\
\text { family careers of people } \\
\text { with dementia: An } \\
\text { integrative review }\end{array}$ & 2018 & $\begin{array}{l}\text { Review } \\
\text { Article }\end{array}$ & $\begin{array}{l}\text { Identify, evaluate and } \\
\text { synthesize the existing } \\
\text { evidence on the use of } \\
\text { mHealth / smartphone apps } \\
\text { as an educational and } \\
\text { support resource for family } \\
\text { caregivers of people with } \\
\text { dementia. }\end{array}$ & $\begin{array}{l}\text { MHealth apps appear to be a } \\
\text { viable intervention for family } \\
\text { caregivers of people with } \\
\text { dementia, despite limited } \\
\text { available research and barriers to } \\
\text { its development and } \\
\text { implementation. }\end{array}$ \\
\hline
\end{tabular}




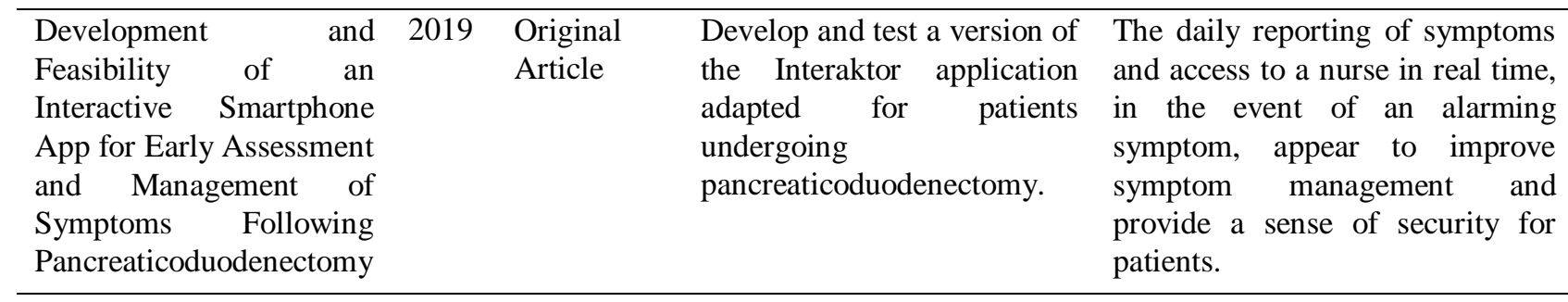

\begin{tabular}{lr}
\hline The Potential of \\
Information & Technology \\
to Navigate & Caregiving \\
Systems: & Perspectives \\
from & Dementia \\
Caregivers &
\end{tabular}

$\begin{array}{lll}2018 \text { Original } & \text { Involve in-depth interviews } \\ \text { Article } & \text { and a beta test of an AD / } \\ & \text { RD caregiver application to } \\ & \text { learn more about how they } \\ \text { currently use technologies } & \text { and how potential } \\ & \text { technological features and } \\ \text { functions can best meet their } & \text { needs. }\end{array}$

needs.

\section{Original} Article

to improve nurses' atrial fibrillation and anticoagulation

knowledge and practice: the EVICOAG study
Evaluate the effectiveness of EVICOAG - a new mHealth intervention, based on smartphones and spaced learning, about nurses' knowledge about atrial fibrillation anticoagulation. -hospital usability and feasibility evaluation of Panda, an app for the management of pain in children at home

Development and
Evaluation of "Chronic
Illness Care Smartphone
Apps" on Nursing
Students" Knowledge,
Self-efficacy, and
Learning Experience

$2018 \begin{aligned} & \text { Original } \\ & \text { Article }\end{aligned}$

Original Article

Assess the usability and feasibility of the Panda app at the hospital before testing it at home.

Develop smartphone-based

virtual experiential nursing apps to care for patients with chronic illnesses, especially patients with hypertension and diabetes, and assessed the effect of apps on nursing students' knowledge, self-efficacy and learning experiences.
The findings suggest that eHealth and individual technologies may not fully meet the needs of caregivers, as they navigate the larger systems in which they provide care.
The EVICOAG intervention improved nurses' knowledge about atrial fibrillation and anticoagulation and influenced the uptake and use of stroke and bleeding risk assessment tools in clinical practice.

Significant barriers to use included lack of flexibility in drug programming, low volume of alert sounds and extra time spent on drug safety checks.

Smartphone apps for treating chronic illnesses are effective learning resources that help students assess patients' health problems and implement nursing care plans to improve patients' conditions.

\begin{tabular}{|c|c|c|c|c|}
\hline $\begin{array}{lr}\text { Electronic } & \text { messaging } \\
\text { intervention } & \text { for } \\
\text { management } & \text { of } \\
\text { cardiovascular risk factors } \\
\text { in type } 2 \text { diabetes } \\
\text { mellitus: A randomized } \\
\text { controlled trial }\end{array}$ & 2017 & $\begin{array}{l}\text { Original } \\
\text { Article }\end{array}$ & $\begin{array}{l}\text { Determine the effectiveness } \\
\text { of an e-mail support service } \\
\text { for the management of } \\
\text { cardiovascular risk factors in } \\
\text { patients with diabetes. }\end{array}$ & $\begin{array}{l}\text { Regular smartphone } \\
\text { communication had a favorable } \\
\text { impact on cardiovascular risk } \\
\text { factors in patients with type } 2 \\
\text { diabetes mellitus. }\end{array}$ \\
\hline $\begin{array}{l}\text { Resource allocation in } \\
\text { pediatric burn care: } \\
\text { Preliminary results of } \\
\text { empowering parents with } \\
\text { smartphone assistance }\end{array}$ & 2018 & $\begin{array}{l}\text { Letter to } \\
\text { the Editor } \\
\text { of } \\
\text { Preliminary } \\
\text { Results }\end{array}$ & $\begin{array}{l}\text { Experiment with some cases } \\
\text { of small wounds (burns) in } \\
\text { children / parents selected } \\
\text { for evaluation. }\end{array}$ & $\begin{array}{l}\text { Confirms that telemedicine can } \\
\text { provide appropriate post-acute } \\
\text { care for burns and long-term } \\
\text { management of patients after a } \\
\text { burn injury. }\end{array}$ \\
\hline $\begin{array}{lr}\text { Advances in } & \text { obstetric } \\
\text { telemonitoring: } & \mathrm{a}\end{array}$ & 2020 & $\begin{array}{l}\text { Review } \\
\text { Article }\end{array}$ & $\begin{array}{l}\text { Identify } \\
\text { contributions, }\end{array}$ & $\begin{array}{l}\text { The area of obstetric } \\
\text { telemonitoring has great potential }\end{array}$ \\
\hline
\end{tabular}


systematic review limitations of obstetric telemonitoring using mobile technologies. to contribute to better pregnancy outcomes, early detection of complications, prevention of complications, providing local intervention even before hospitalization.

Respondents were interested in these new technologies and wanted to offer them to their patients. However, our study highlighted several issues, as respondents doubted the reliability of these devices and feared that they would harm the therapeutic relationship. affect this acceptability.

Clinical Decision Support 2018 Review Describe clinical decision
Tools Improving Cancer Article support tools and advances Care in health information technology currently used in a cancer center designated by the National Cancer Institute to help achieve the Institute for Healthcare Improvement's Triple Objective project.

Cancer patients, cancer nurses and oncologists have an increasing amount of clinical decision support tools available to help achieve the Institute for Healthcare Improvement Triple Objective.

Analyze telehealth solutions, mobile applications and portable devices that currently affect patients, caregivers and providers working in the oncology field.
Telehealth, $\quad$ Mobile 2018 Review Applications, and Article Wearable Devices are Expanding Cancer Care Beyond Walls
Present

The use of advanced medical technologies at home: a systematic review of the literature
Review
Article trends and experiences with the use of advanced technologies at home. medical
Research on medical technologies used at home increased considerably until 2015. Much is already known about topics, such as user experiences; security, risks, incidents, and complications; and design and technological development.

During the transition, mothers expressed greater anxiety, fear and stress about life-threatening situations that did not decrease over time, despite the discharge education received. three months after the initial discharge from the NICU.

Infant from the NICU to

Home

\begin{tabular}{|c|c|c|c|}
\hline Smartphone-Based Health & 2017 & Review & Check if smartphone \\
\hline Technologies & & Article & technologies have been used \\
\hline $\begin{array}{l}\text { Dementia } \\
\text { Opportunities, }\end{array}$ & & & $\begin{array}{l}\text { to support and assist } \\
\text { dementia patients. }\end{array}$ \\
\hline
\end{tabular}

Challenges, and Current

Practices individual apps available have limited functions (compared to the complex needs of caregivers) and little has been done to extend $\mathrm{HC}$ caregiver apps to Hispanic
Nurses who care for cancer and mobile health in this unique population. populations 
According to the table presented, it is observed that 2018 was the year with the largest number of publications (nine), followed by 2019 (three), 2017 (two) and 2020 (two). Regarding the type of study, mostly original studies (nine) were identified, soon after, review articles (six) and a letter to the editor with preliminary results (one).

In the analysis of the search and of the selected studies, it was found that the published literature on applications and home care in nursing is still very incipient, making clear the need for greater investment in this area of health technology directed to home care, in addition to the dissemination knowledge for professionals who did not have such contact during training.

\section{Discussion}

\subsection{Use of Healthcare Applications}

The use of mobile applications in patient care certainly presents an evolution in the care, management and cost reduction scenario for institutions providing health services, in addition to the possibility of generating more jobs, with the nursing team playing a key role and autonomous in this process.

A study carried out in long-term care facilities for the elderly with a focus on reducing pressure injuries, a Quality Assurance and Performance Improvement plan and Root Cause Analysis were developed to increase the quality of the wound care program available to residents. From the development of a digital solution for external monitoring, as the elderly lived on site, its focus was directed to the tracking and management of wounds, in addition to the creation of related performance metrics. It was observed that the real-time access to the patient's situation from an electronic record provided the best management and the incidence drop from $12.99 \%$ to $2.9 \%$ in just 1 year.

Study performed with patients who underwent pancreaticoduodenectomy for pancreatic cancer treatment and were discharged, implemented an application for daily monitoring of these patients with the participation of a nurse, in real time, who responded to requests and daily reports. It was confirmed that the project was successful in providing self-care, and the daily report completed by the patient or caregiver had an adherence of $84 \%$, which demonstrates that the daily or periodic monitoring of patients implies better and greater management of cases, increasing the well-being and quality of life of patients and their families / caregivers.

These data corroborate the question of the importance, not only of providing healthcare services via applications, but of monitoring this patient, as the patient / caregiver / family member does not always have adequate knowledge to identify health needs.

When we talk about applications directed to health care, it appears that many exist to answer questions and guide patients / caregivers / family members from educational materials available and trained professional chats. However, for home care itself, it is not yet widely used.

The term 'home care' has been used for individuals assisted by caregivers, which is not indicated, given that home health care must be performed by a professional qualified in Health Sciences. This fact is verified in two of the studies selected, that remote assistance applications generate greater doubts for patient caregivers, in this case patients with dementia, as technical and scientific assistance information or possible diagnosis when received by a layman are dangerous due to lack of adequate knowledge to understand them, besides of not knowing the practice itself. The two studies also infer that when a patient is at home, the greatest resource used to obtain information is not professional consultations or guidance, it is information made available in major media on the Internet, increasing the possibility of worsening of the condition, serious errors that can lead the patient to hospital institutionalization and even death.

Study carried out from the development of a messaging application for regular communication between professionals and patients with type 2 diabetes mellitus concluded that there was no significant difference in message assistance, however, an increase in the prevention of cardiovascular risks among diabetic patients. Confirming that the assistance itself is not effective only with messages, but guidelines for preventing risk factors and injuries do.

In a research, still under development, from a preliminary study, on the development of an application for the management of care for children with wounds from burns, emphasizes that when parents follow the child's hospitalization process, they observe and learn about changing and performing dressings as well such as wound cleaning, however, wound evaluation requires the presence of a qualified professional.

From the realization of a systematic review on health care by applications directed to pregnant women, infer that telemonitoring allows the early identification of symptoms, however, the interventions and procedures that may 
be necessary during pregnancy and the puerperium require the presence of a qualified professional, even if at home, not needing the patient to go to a health unit.

Another parameter on health care via an existing application is robot care based on algorithms. Study conducted to evaluate the effectiveness of an application developed for mental health care and identification of the four domains of acceptability: usefulness, usability, reliability, and risk. It was concluded that nursing students accepted the question of new technologies for the benefit of assistance, however, the use of digital phenotyping was not accepted due to lack of confidence, in addition to believing that it would harm the therapeutic relationship with the patient who was already suffering from depression. And still in relation to mental health care, it appears that not all professionals are trained to care for patients with compromised mental health, psychological and psychiatric disorders and, in relation to applications, there is still no effective assistance for people with Alzheimer's Disease.

One of the populations that needs a closer look for individualized care are cancer patients, who already suffer from the disease, painful treatments with loss of identity, whether family, personal, social, being possible to be in the comfort of their home, close to people who love, there is certainly an increase in the well-being of this patient. And it is in this scenario that a study emphasizes that the nurse is the protagonist of home care and applications.

Home care finds a rich field of opportunities, considering that in the last 10 to 15 years, there has been a significant increase in patients with comorbidities and use of hospital devices at home, in addition to fragile individuals, such as newborns and the elderly, recently from Intensive Care Units returning home. In this scenario, it is possible to verify the importance of a qualified professional to meet this demand.

\subsection{Application Development for Health Care, Assessment and Education}

With health technology as the future of care, there are many ongoing studies, which is the case with the development of an application for monitoring and home care in the case of a child / adolescent in the postoperative period with pain. In the first phase of the development of this application, called Panda, guidance on the care of children or adolescents was made available, as well as alerts and medication programs for nurses, parents, and adolescents, as well as checklists made available daily or periodically in relation to the care of each patient, individually. In the second phase, the feasibility of using the application was also assessed with patients in the postoperative ward with feedback from everyone involved. Many weaknesses were found, and it is still in the process of improvement for further feasibility analysis in the home scenario.

All those responsible and managers of mobile applications that involve online or face-to-face assistance (in the home modality) should keep in mind that it is not enough to just offer a health service, it is necessary to train the health professionals involved, using protocols as well as standardization procedures, consultations, and services in general, in addition to continuing education and assessment (intra-application) tools for generating performance metrics and meeting patient needs.

It appears that the development of an application for home care or even for assistance via online with trained professionals generates time, bias, and constant evaluations, in addition to needing a record of the patient's situation (medical record), because, after all, it's about lives. Regarding the guarantee of continuity of treatment and care, a study states that one of the greatest requirements of applications that assist in health care is to have a record with patient information, enabling professionals to access it before starting any care. In this way, applications become tools to aid clinical decision making, enabling the improvement of the patient's prognosis.

In terms of education, it is highlighted that all the technology we have in the current world and those in development, in addition to not being part of the training of nursing professionals, there is no incentive to acquire such knowledge, which become barriers to the development of other applications, in addition to the low adherence and poor quality of use of these platforms, which was verified in a study on the education of undergraduate nursing students on the development and evaluation of mobile applications for the management of patients with chronic diseases.

\section{Study Limitations}

Even though the MeSH was correct, it was decided to remove the "Culturally Appropriate Technology" from the search for not presenting results. Given this circumstance, it presents a weakness of the study, such as the incorrect use of descriptors by studies published in the main health and nursing databases. 


\section{Contributions to the Area of Nursing and Public Health}

This study can contribute to the awakening to the development of new health technologies that help both nursing professionals and patients. Home care applications provide extra income for health professionals, in addition to their organization, as the electronic medical record and simultaneous training subsidize science-based decision making. For society, it is necessary to remember that most patients who are discharged from hospital still need home care, and that many are unaware of this possibility, especially with the integration of home consultation, analyzing each case, each circumstance, each reality of life and setting up an adequate and individualized planning and guiding caregivers / family members / guardians.

\section{Conclusion}

It was found that we are experiencing a growing wave in relation to biomedical technology, with the development of applications for management, monitoring, guidance, online assistance, and face-to-face assistance scheduling, in which the need for trained and qualified professionals to act is remarkable. Directly with the patient and understand and use the technological tools of contact with the patient / caregiver / family.

There are many studies on the development of applications for health care, however the practice of home care through (initial and constant) an application is still taking its first steps, just check that there are not many studies on the subject.

Continuing education should be a fixed pillar in care, regardless of the form in which care is provided, enabling patients to receive care for their health needs in an effective and qualified manner.

It is concluded that assistance applications have their validity and importance, such as monitoring and welcoming the patient, as well as recording the patient's history in each application, however, assistance at home prevents the patient's displacement, waits in service queues, in addition to consisting of individualized and humanized care, as it values the holistic view that nursing and health professionals in general must have to provide assistance.

\section{References}

Alves, D. S., Times, V. C., Silva, E. M. A., Melo, P. S. A., \& Novaes, M. N. (2020). Advances in obstetric telemonitoring: a systematic review. International Journal of Medical Informatics, 134, 104004. https://doi.org/10.1016/j.ijmedinf.2019.104004

Andrade, A. M., Silva, K. L., Seixas, C. T., \& Braga, P. P. (2017). Atuação do enfermeiro na atenção domiciliar: uma revisão integrativa da literatura. Rev. Bras. Enferm., 70(1), 201-219. https://doi.org/10.1590/0034-7167-2016-0214

Au, Y., Holbrook, M., Skeens, A., Painter, J., McBurney, J., Cassata, A., \& Wang, S. C. (2019). Improving the quality of pressure ulcer treatment in a nursing facility. Int $J$ ferida., 16, 550-555. https://doi.org/10.1111/iwj.13112

Bardin, L. (2011). Análise de conteúdo. São Paulo: Edições.

Bourla, A., Mouchabac, S., Ogorzelec, L., Guinchard, C., \& Ferreri, F. (2020). Are student nurses ready for new technologies in mental health? Mixed-methods study. Nurse Education Today, 84, 104240. https://doi.org/10.1016/j.nedt.2019.104240

Brown, E. L., Ruggiano, N., Juanjuan, L., Peter, J., Clarke, E. S., \& Kay, V. H. (2019). Smartphone-based health technologies for dementia care: opportunities, challenges, and current practices. Sage Journals, 38(1). https://doi.org/10.1177/0733464817723088

Cannon, C. (2018). Telehealth, mobile applications, and wearable devices are expanding cancer care beyond walls. Seminars in Oncology Nursing, 34(2), 118-125. https://doi.org/10.1016/j.soncn.2018.03.002

Carlos, D. A. O., Magalhães, T. O., Filho, J. E. V., Silva, R. M., \& Brasil, C. C. P. (2016). Concepção e avaliação de tecnologia mhealth para promoção da saúde vocal. RISTI, (19), 46-60. https://doi.org/10.17013/risti.19.46-60

Ferguson, C., Hickman, L. D., Phillips, J., Newton, P. J., Inglis, S. C., Lam, L., .. Bajorek, B. V. (2019). An mHealth intervention to improve nurses' atrial fibrillation and anticoagulation knowledge and practice: the EVICOAG study. European Journal of Cardiovascular Nursing, 18(1), 7-15. https://doi.org/10.1177/1474515118793051 
Guimarães, C. P. (2014). Assistência domiciliar do enfermeiro: Planejamento estratégico situacional - Unidade Básica de Saúde Almerindo Alves Barbosa Farias do Município de Janaúba/MG. Especialização em Atenção Básica em Saúde da Família. Universidade Federal de Minas Gerais [Internet]. Montes Claros MG. $2014 \quad$ [cited $2020 \quad$ May 20]. Retrieved from https://www.nescon.medicina.ufmg.br/biblioteca/imagem/4527.pdf

Gustavell, T., Langius-Eklöf, A., Wengström, Y., Segersvärd, R., \& Sundberg, K. (2019). Development and feasibility of an interactive smartphone app for early assessment and management of symptoms following $\begin{array}{llll}\text { pancreaticoduodenectomy. } & \text { Cancer } & \text { Nursing, } & \text { 42(3), }\end{array}$ https://doi.org/10.1097/NCC.0000000000000584

Haken, I. T., Allouch, S. B., \& Van Harten, W. H. (2018). The use of advanced medical technologies at home: a systematic review of the literature. BMC Public Health, 18(284). https://doi.org/10.1186/s12889-018-5123-4

Jiyoung, K., \& Eunyoung, S. (2018). Development and evaluation of "chronic illness care smartphone apps" on nursing students 'knowledge, self-efficacy, and learning experience. CIN: Computers, Informatics, Nursing, 36(11), 550-559. https://doi.org/10.1097/CIN.0000000000000447

Lima, A. P. S., Chianca, T. C. M., \& Tannure, M. C. (2015). Avaliação da assistência de enfermagem utilizando indicadores gerados por um software. Rev Latino-Am Enferm., 23(2), 234-241. https://doi.org/10.1590/0104-1169.0177.2547

Martinez, R., \& Rode, H. (2018). Resource allocation in pediatric burn care: Preliminary results of empowering parents with smartphone assistance. South African Medical Journal, 108(11), 889-890. https://doi.org/10.7196/SAMJ.2018.v108i11.13587

Penha, J. R. L., Fernandes, F. A., Oliveira, C. C., Oliveira, R. D., \& Barros, E. F. (2020). Validação e utilização de novas tecnologias na saúde e educação: uma revisão integrativa. Rev. Interdisciplin Promoç Saúde, 1(3), 199-206. Retrieved from https://online.unisc.br/seer/index.php/ripsunisc/article/view/12580/7728

Rathnayake, S., Moyle, W., Jones, C., \& Calleja, P. (2018). Applications of mhealth as an educational and support resource for family caregivers of people with dementia: an integrative review. Demência, 18(7-8), 3091-3112. https://doi.org/10.1177/1471301218768903

Ronghua, F., \& Xuexue, D. (2018). Electronic messaging intervention for management of cardiovascular risk factors in type 2 diabetes mellitus: A randomized controlled trial. J Clin Nurs., 27, 612-620. https://doi.org/10.1111/jocn.13962

Ruggiano, N., Brown, E., Shaw, S., Geldmacher, D., Clarke, P., Hristidis, V., ... Bertram, J. (2019). The potential of information technology to navigate caregiving systems: perspectives from dementia caregivers. Journal of Gerontological Social Work, 62(4), 432-450. https://doi.org/10.1080/01634372.2018.1546786

Silva, K. L., Sena, R. R., Seixas, C. T., Feuerwerker, L. C. M., \& Merhy, E. E. (2010). Home care as change of the technical-assistance model. Rev. Saúde Pública., 44(1), 166-176. https://doi.org/10.1590/S0034-89102010000100018

Silva, K. L., Sena, R. R., Silva, P. M., Braga, P. P., \& Souza, C. G. (2012). Supplementary home health care services and the inclusion of nursing in Belo Horizonte / Minas Gerais (Brazil). Acta Paul Enferm., 25(3), 408-414. https://doi.org/10.1590/S0103-21002012000300014

Silva, L. K., Sena, R. R., Silva, P. M., Souza, C. G., \& Martins, A. C. S. (2014). The nurse's role in home care: its implications for the traning process. Cienc Cuid Saude, 13(3), 503-510. Retrieved from http://www.periodicos.uem.br/ojs/index.php/CiencCuidSaude/article/viewFile/19227/pdf_334

Souza, M. T., Silva, M. D., \& Carvalho, R. (2010). Revisão integrativa: o que é e como fazer. Einstein (São Paulo)., 8(1), 102-106. https://doi.org/10.1590/s1679-45082010rw1134

Stillman, R. C. (2018). Clinical decision support tools improving cancer care. Seminars in Oncology Nursing, 34(2), 158-167. https://doi.org/10.1016/j.soncn.2018.03.007

Sun, T., Dunsmuir, D., Miao, I., et al.. (2018). In-hospital usability and feasibility evaluation of Panda, an app for the management of pain in children at home. Pediatr Anesth, 28, 897-905. https://doi.org/10.1111/pan.13471 
Toly, V. B., Blanchette, J. E., Alhamed, A., \& Musil, C. M. (2018). Mother's voice related to caregiving: the transition of a technology-dependent infant from the NICU to home. Neonatal Network, 18(2). https://doi.org/10.1891/0730-0832.38.2.69

\section{Copyrights}

Copyright for this article is retained by the author(s), with first publication rights granted to the journal.

This is an open-access article distributed under the terms and conditions of the Creative Commons Attribution license (http://creativecommons.org/licenses/by/4.0/). 